\title{
CULTURAS DOCENTES E CULTURA ORGANIZACIONAL NUM INSTITUTO FEDERAL DE EDUCAÇÃO
}

https://dx.doi.org/10.5902/2318133868214

\author{
Jássio Pereira de Medeiros ${ }^{1}$
}

\section{Resumo}

Neste texto, relata-se os resultados de um estudo que teve por objetivo analisar a influência de subculturas ou microcampos docentes nas variáveis da cultura organizacional do IFRN, a partir do contexto de expansão da rede de educação profissional. Para tanto, partiu-se de referências de modelo teórico relacionado com cultura escolar, cultura organizacional escolar e cultura organizacional de escola. Foi desenvolvido um estudo de natureza qualitativa, por meio do método do estudo de caso, e que adotou o IFRN como campo de observação. Para a coleta de dados foi administrado um inquérito por questionário junto a 213 professores a instituição. Foi possível constatar a existência de microcampos docentes e subculturas inseridas nesses microcampos, capazes de interferir na percepção da cultura organizacional. Os conflitos, jogos de interesses e ambiguidades na formação dessas subculturas evidenciaram manifestações culturais diferenciadoras e fragmentadores no interior dos microcampos docentes.

Palavras-chave: educação profissional; cultura organizacional; cultura escolar; subculturas. docentes.

\section{TEACHING CULTURES AND ORGANIZATIONAL CULTURE IN A FEDERAL EDUCATION INSTITUTE}

\section{Abstract}

In this paper, we report the results of a study that aimed to analyze the influence of subcultures or teaching microfields on the variables of the IFRN's organizational culture, based on the context of expansion of the Professional Education Network. For that, we started from references of a theoretical model related to school culture, school organizational culture and organizational culture of the school. A qualitative study was developed using the case study method, which adopted the IFRN as a field of observation. For data collection, a questionnaire survey was administered to 213 professors at the institution. It was possible to verify the existence of teaching microfields and subcultures inserted in these microfields, capable of interfering with the perception of organizational culture. The conflicts, games of interests and ambiguities in the formation of these subcultures evidenced differentiating and fragmenting cultural manifestations within the teaching microfields.

Key-words: professional education; organizational culture; school culture; under cultures; teachers.

\footnotetext{
1 Instituto Federal de Educação, Ciência e Tecnologia do Rio Grande do Norte, Brasil. E-mail: jassio.pereira@ifrn.edu.br. 


\section{Introdução}

funcionamento das organizações voltadas para a educação profissional e tecnológica no Brasil se apresenta como fenômeno complexo e multifacetado, envolvendo diversos tipos de instituições, assim como diferentes relações entre professores, alunos e servidores técnico-administrativos, principalmente na nova configuração dos institutos federais de educação, ciência e tecnologia (Gianezini, 2011).

Esses institutos surgiram no contexto de expansão e valorização da educação profissional, desencadeado a partir do ano de 2003, mediante um plano estruturante de expansão da rede federal de educação profissional e tecnológica, atuando em cursos técnicos, licenciaturas e graduações tecnológicas, além de especializações, mestrados profissionais e doutorados, voltados, principalmente, para a pesquisa aplicada de inovação tecnológica e formação de professores.

De acordo com Pacheco (2011), essa ampla atuação dos IFs, no que diz respeito aos diferentes níveis de ensino, representou, para os profissionais da educação, um espaço mais complexo de construção de saberes, de tal forma que, enquanto que possibilita o diálogo simultâneo da educação básica até a pós-graduação, requer dos docentes a criação de vínculos em diferentes níveis e modalidades de ensino, a busca de metodologias que melhor se apliquem a cada ação, assim como o estabelecimento da indissociabilidade entre ensino, pesquisa e extensão. Tais necessidades podem ter implicações diretas na forma de atuação do professor e na maneira como ele percebe 0 ambiente de trabalho.

Acrescente-se a esse novo contexto uma estrutura administrativa multicampi, que define o território de abrangência de suas ações, mas, de outra forma, também delimita a necessidade de contratação de professores vindos de outras localidades e que não estabelecem moradia fixa no município onde o campus está localizado ou passam a viver distante de suas famílias. Ou seja, a nova institucionalidade percebida a partir do plano de expansão da rede federal de educação profissional e tecnológica, apresenta diversos desafios à forma de funcionamento das diversas organizações escolares.

Assim, considerando essas novas exigências impostas pelo núcleo central de gestão da educação, por melhor atuação dos profissionais responsáveis pelos serviços educacionais e, também, maior demanda pela prestação desses serviços, objetivou-se analisar a influência de subculturas ou microcampos docentes nas variáveis da cultura organizacional do IFRN, a partir do contexto de expansão da rede de educação profissional.

\section{Cultura organizacional}

Tendo em vista que pelo estudo buscou-se pautar a partir de uma perspectiva mais crítico-reflexiva, realizou-se uma revisão de escritos sobre a cultura organizacional. Assim, privilegiou-se as abordagens culturais de natureza pluridimensional, que contemplam a coexistência de subculturas (Riley, 1983) ou contraculturas (Martin; Siehl, 1983). Isso significa um posicionamento baseado numa visão subjetivista e interpretativa da realidade, influenciado por fatores característicos de estudos antropológicos e sociológicos. 
Para respaldo do presente estudo, mobilizam-se as perspectivas discutidas por Smircich (1983) e Martin (1992), por as considerar mais adequadas à proposta de investigação. Smircich (1983) apresenta uma grelha interpretativa dos estudos sobre cultura organizacional alicerçada em duas vertentes, uma associada a uma perspectiva funcionalista, que tratava da observação da cultura enquanto variável dependente ou independente, interna ou externa da organização, isto é, a cultura representaria algo que a organização possui, enquanto a outra interpretava a cultura como algo que a organização é, ou seja, a cultura enquanto metáfora da organização.

Destaca, pois, que a cultura enquanto variável está associada a uma corrente tradicional, objetivista e positivista. Os autores que defendem tal posicionamento reconhecem que as organizações produzem traços culturais mais ou menos distintos, tais como valores, normas, rituais, cerimônias e expressões verbais que, em conjunto, afetam o comportamento dos empregados e dirigentes e, também, promove um senso de identidade, o que Ihes facilita maior envolvimento com ela, assegura a estabilidade do sistema e serve como instrumento de orientação e modelagem do comportamento (Ferreira et al., 2002). Essa abordagem considera dois tipos de variáveis: o primeiro consideraria a cultura uma variável independente, externa à organização, isto é, a cultura da sociedade em que se insere a organização e que é trazida para dentro por seus integrantes. O segundo tipo assumiria a cultura como variável interna à organização, considerando que as organizações, além de produzirem bens e serviços, também produziriam produtos culturais, como lendas, ritos, símbolos, o que equivale ao resultado do desempenho e de representações dos indivíduos nas organizações.

De outra forma, segundo Smircich (1983), a cultura enquanto metáfora organizacional, segue uma perspectiva fenomenológica ou hermenêutica e aborda as organizações como fenômenos culturais em essência, fundamentando-se na antropologia para desenvolver novas teorias e paradigmas. Nesse sentido, as organizações são concebidas como manifestações que expressam a consciência humana, e, por essa razão, devem ser analisadas levando em conta seus aspectos simbólicos que tornam possível a ação compartilhada.

Martin (1992), por sua vez, parte do pressuposto de que não existe uma só cultura, e procura reduzir a ambiguidade conceitual em torno da problemática, identificando três perspectivas culturais: Integração - enfatiza uma visão comum e a partilha de valores pelos membros da organização; Diferenciação - focaliza a oposição e diferenciação dos valores expressos pelos atores organizacionais; Fragmentação - incide sobre as ambiguidades e as desconexões organizacionais.

De maneira geral, Martin (1992) estrutura as formas de estudar a cultura em três perspectivas, mediante as quais a autora tenta estabelecer tipos ideais que envolveriam opções teórico-metodológicas claras e distintas, passíveis de serem escolhidas segundo a subjetividade dos pesquisadores. Apesar de propor, conceitualmente, uma divisão, a autora sugere que estudiosos da área utilizem, simultaneamente, as três abordagens visto que, com isto, haveria uma complementaridade e superação das limitações individuais de cada uma delas. Além disso, essa combinação proporcionaria interpretações mais completas sobre a cultura organizacional, coisa que cada abordagem, isoladamente, não oferece. 
A primeira abordagem, da integração, teria um quadro teórico inspirado no paradigma funcionalista e gerencialista, justificando, assim, uma visão homogênea da cultura e que se orienta pelo consenso no nível organizacional. Já a abordagem da diferenciação, com enfoque crítico, também supõe um consenso, mas num nível subcultural. Ou seja, dentro da organização, existiriam diferentes subculturas, atuando de maneira harmônica, em independência ou em conflito, o que poderia propiciar análises acerca das dinâmicas de poder, desigualdade e dominação nas organizações. Por fim, a abordagem da fragmentação, com enfoque descritivo, observa a organização a partir de um contexto de ambiguidade, ou multiplicidade de interpretações, de falta de consenso, enfatizando a heterogeneidade cultural. De maneira resumida, é possível depreender que a integração seria caracterizada pela harmonia, a diferenciação pelo conflito e a fragmentação pela ambiguidade.

A mobilização desse referencial teórico se presta, pois, à análise e ao conhecimento da unidade escolar, visto que a escola é considerada um sistema sociocultural, constituído por grupos que se relacionam, vivenciam códigos e sistemas de ação. A organização educativa constitui, nesse contexto, um espaço singular para o estudo dos aspectos culturais. Primeiro, por ser lócus no qual se realizam trocas simbólicas, criação e difusão de mensagens, codificação e descodificação de gestos e linguagens. Depois, por ser a instituição destinada pelo Estado e pelos grupos sociais para desempenhar papel prioritário no estabelecimento dos padrões da sociedade, dos canais e limites da comunicação no todo social (Sarmento, 1994).

\section{Cultura organizacional em contexto escolar}

Com vistas a promover a exploração dessas dimensões, buscou-se apoio no enquadramento analítico proposto por Torres (2005). Alicerçada em dois eixos principais, a grelha analítica representada na figura 1, adaptado de Torres (2005), busca demonstrar os diferentes níveis de implicação, articulação e de interdependência entre as respectivas categorias pertencentes a um eixo horizontal - fora/dentro - e outro eixo vertical estrutura/ação - no processo de construção da cultura organizacional em ambientes escolares.

De acordo com Torres (2005, a intersecção entre os dois eixos resulta num recorte de quatro quadrantes, expressos por fatores que implicam a construção cultural e simbólica:

O quadrante 1, na zona de convergência estrutura/dentro, destaca a presença da estrutura formal no processo de construção da cultura, demonstrando uma relação imperativa da primeira para com a segunda; o quadrante 2, localizado na intersecção entre a 'ação' e o 'dentro', enfatiza a importância do indivíduo no interior da organização e, consequentemente, na produção da sua cultura; o quadrante 3, representa as inter-relações entre a 'ação' e o 'fora', e destaca aspectos de socialização extra-escolar vivenciadas pelos atores escolares e a influência desses aspectos na formação da cultura organizacional escolar; por fim, o quadrante 4 , presente no 
encontro dos campos estrutura/fora, identifica a predominância dos padrões estruturais provenientes do nível político e da esfera profissional no enquadramento das orientações normativas $e$ culturais da organização escolar. (p. 444)

Figura 1 -

Processo de construção da cultura organizacional da escola.

\section{Estrutura/Formal}

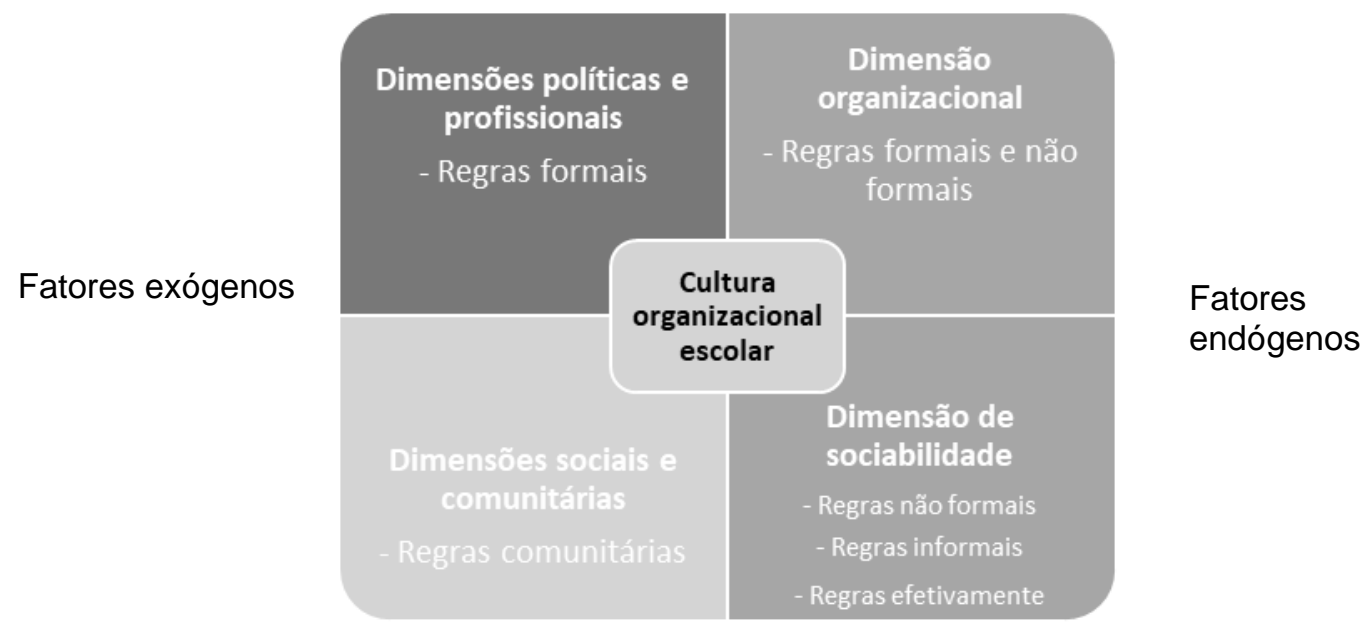

Ação/Informal

Fonte: adaptado de Torres (2005).

De outro ponto de vista, a observação da figura 1 permite identificar diferentes dimensões da cultura organizacional escolar a partir do cruzamento dos fatores internos e externos com os fatores formais e informais da escola. A dimensão nomeada por Torres (2005) de política e profissional seria consequência da relação entre fatores exógenos à escola e os aspectos formais que a envolvem. Essa dimensão pode ser analisada considerando as regrais formais, elaboradas externamente, e a maneira como a escola as implementa. Ainda no que diz respeito aos fatores exógenos intervenientes na realidade escolar, mas agora observando sua relação com os aspectos informais, Torres (2005) propôs a dimensão social e comunitária. $O$ estudo dessa dimensão analisaria o que a autora chamou de regras comunitárias, as quais seriam derivadas da comunidade externa que circunda a escola, como empresas, pais, entre outros atores sociais.

Já as dimensões associadas aos fatores endógenos seriam a dimensão organizacional e a dimensão de sociabilidade. A dimensão organizacional considera a relação dos fatores endógenos com os aspectos formais da escola. Para tanto, seu estudo aborda as regras formais e não formais, isto é, as regras formalmente instituídas e as regras menos estruturadas formalmente e que perpassam por interpretações das regras formais. A dimensão de sociabilidade pressupõe a interação dos fatores endógenos com os aspectos informais. As regras informais representam regras não 
estruturadas formalmente, voltadas para a ação dos atores organizacionais, podendo estar orientadas no sentido de oposição às regras formais. As regras efetivamente atualizadas, por sua vez, tratam da ação que, de fato, é praticada pela escola, independentemente das orientações externas existentes.

Partindo para uma perspectiva micro de análise, tem-se a observação dos fenômenos que se interpõem entre o ator e o sistema. Tal abordagem reside na descrição das manifestações de uma ou mais culturas no interior da escola e na apreciação de suas relações com o instituído da cultura escolar hegemônica. Como lembra McLaren (1997), historicamente poucos estudos, em especial no Brasil, estão voltados para as questões culturais, uma vez que, apenas recentemente novas possibilidades de estudos surgiram nesse campo, dirigidas para aspectos do multiculturalismo ou diversidade cultural.

Nesse contexto, todo o fenômeno de expansão da rede de educação profissional no Brasil e suas relações com a educação e a escola se mostram como um campo relevante de estudos. Assim, pretende-se buscar uma nova visão da organização escolar, ancorada num modelo teórico de análise, baseado na metáfora cultural como um recurso que vai além da imagem da organização educativa observada apenas do ponto de vista de seus aspectos burocráticos. Ampliam-se, dessa forma, as possibilidades de conhecimento da sua dinâmica interna.

A escola será visualizada, portanto, como uma entidade sociocultural, constituída por grupos que, em suas mútuas relações, vivenciam códigos e sistemas de ação, fazendo dela instrumento e produto da cultura. Nessa perspectiva, a escola não pode ser reduzida à sua estrutura de cargos e funções, tampouco aos graus e modalidades de ensino ministrados, ou ao somatório de salas de aula onde os professores são individualmente responsáveis pela prática pedagógica que desenvolvem. Ela constitui um organismo vivo e dinâmico que possui, além de uma estrutura burocrática, uma constituição cultural e simbólica que lhe confere vida própria e lhe permite responder às demandas e limitações, impostas pelo sistema que a mantém e pelo meio social a que atende (Cândido, 1977).

Ao considerar a unidade escolar em todas as suas dimensões, essa abordagem permite que se levem em conta os diferentes interesses e motivações, manifestados pelos atores presentes na vida da instituição, individualmente ou em grupos, e os conflitos que aí se manifestam.

Depreende-se, portanto, que a cultura organizacional, seja nas organizações de maneira genérica, seja no contexto das organizações escolares, não pode ser considerada monolítica ou harmônica, no que tange às relações entre os integrantes da escola. $O$ que se tem é a instituição escolar formada por um tecido de subgrupos possuidores de uma cultura própria e com uma forma particular de perceber sua vida dentro da escola, como é o caso dos docentes.

\section{(Sub)cultura docente}

De acordo com Julia (2001), a realização de um recorte cronológico é fundamental para se proceder a investigações científicas sobre cultura escolar, na medida em que ela envolve três elementos essenciais: o espaço de funcionamento da escola, os cursos 
seriados e o corpo profissional. Dessa forma, para Julia (2001), um dos elementos imprescindíveis para análise da organização educativa são os indivíduos responsáveis pelo seu funcionamento.

Um dos grupos existentes na organização escolar e que contribui para desenhar o cenário educativo é a classe docente. Essa classe, como grupo social e profissional que é, também apresenta a sua cultura, dentro da cultura organizacional escolar. O estudo dessa (sub)cultura docente no contexto de uma organização educativa é complexo, visto que o conhecimento, os valores, as normas e a forma de comportamento de seus integrantes se organizam de diversos modos, existindo no interior da organização escolar uma acentuada heterogeneidade, que compreende diversos níveis de ensino, escalões salariais, faixas etárias de alunos, conteúdos curriculares, localização de escolas, status, recursos disponíveis, condições de trabalho etc. Assim, entende-se que, no interior das escolas, existem diversas subculturas. Na visão de Lima (2002), as culturas dos professores se diferenciam "não só entre escolas, como também entre grupos de professores de cada escola” (p. 25).

De forma semelhante, Hargreaves (1998) também menciona a existência de diferentes culturas entre distintos grupos docentes. Para tanto, esse autor distingue duas dimensões fundamentais: conteúdo e forma. Por conteúdo compreendem-se os valores, crenças, hábitos, atitudes, ou seja, o que se pode observar a partir do que os professores pensam, dizem e fazem. Já por forma, entendem-se os tipos de relações estabelecidas entre professores, em suas condições concretas.

No cotidiano da escola, os professores agrupam-se em diferentes circunstâncias e situações que constituem os microcampos docentes, os espaços em que circulam saberes e códigos próprios, afetos ao grupo. A mais conhecida dessas agremiações são os departamentos ou a área de conhecimento, ou seja, a junção de professores de uma mesma disciplina ou área de conhecimento. Podem existir também microcampos relativos à titulação dos professores, ao tempo de trabalho da instituição, entre outros. Hargreaves (1998) denomina isso de balcanização, ou cultura balcanizada, o que, frequentemente, leva a situações em que conseguir um consenso ou estabelecer acordos, como as reivindicações básicas da categoria, entre os diferentes grupos é difícil. Visualizando esse cenário, percebe-se que a cultura docente se constitui numa totalidade composta de diversos microcampos.

Nesse sentido, parte-se, então, para uma explicitação do conceito de cultura docente. O conceito de cultura apresenta não somente uma natureza cognitiva, mas também axiológica e material, visto que integra ideias e perspectivas, além de valores e normas e ainda rituais, símbolos e artefatos. Trata-se, pois, de um conceito que procura contemplar a complexidade das formas simbólicas de articulação dos professores com 0 mundo das escolas e da educação. É dessa forma que alguns autores definem cultura docente, ou seja, a cultura profissional-ocupacional que trata de um conjunto de crenças, valores, hábitos e dispositivos simbólicos, partilhados por uma comunidade de professores, assim como os modos politicamente corretos de pensar, sentir, atuar e se relacionar entre si em articulação com o contexto em que decorre a prática profissional e os seus processos de formação e socialização (Sarmento, 1994; Hargreaves, 1998; Pérez Gómez, 2001). 
As culturas dos professores, contudo, deverão ser perspectivadas, não apenas em termos de conhecimentos, de valores, crenças, representações, normas e concepções, mas também de comportamentos e práticas, ou seja, modos de ação e padrões de interação consistentes e relativamente regulares que os professores interiorizam, produzem e reproduzem durante as suas experiências de trabalho. Essa cultura docente também é efeito das pressões e expectativas externas, dos processos de socialização e dos demais agentes envolvidos. Como consequência desses comportamentos e práticas, ao assumir as culturas docentes de sua escola, os professores se sentem seguros e protegidos pelo grupo, que passa a oferecer força e sinais de identidade da profissão.

A partir do reconhecimento de suas forças e identidade profissional, a cultura docente também pode se comportar como obstáculo às mudanças, às veze, propostas pelas reformas educativas, implantadas a partir do exterior da escola. Viñao Frago (1996) já afirmava que um dos principais problemas com que as reformas se confrontam é o de, sistematicamente, ignorarem a existência de um conjunto de tradições e regularidades institucionais sedimentadas ao longo do tempo, que influenciam profundamente a forma como os professores organizam as suas atividades acadêmicas, como lecionam as aulas e como governam a vida da escola. Foi esse cenário que gerou inquietação para se investigar a influência de (sub)culturas ou microcampos docentes nas variáveis da cultura organizacional do IFRN, a partir do contexto de expansão da rede de educação profissional.

\section{Procedimentos metodológicos}

A abordagem metodológica mobilizada neste estudo inscreve-se num paradigma predominantemente qualitativo, tendo em vista que objetiva traduzir, compreender e expressar o sentido dos fenômenos do mundo social, visando reduzir a distância entre indicador e indicado, entre teoria e dados, entre contexto e ação (Van Maanen, 1979).

Com base na afirmação de Stake (1999, p. 236), de que o "estudo de caso não é uma escolha metodológica, mas uma escolha do objeto a ser estudado", o presente estudo procura focalizar um fenômeno particular, qual seja, a influência de (sub)culturas ou microcampos docentes nas variáveis da cultura organizacional, levando em conta seu contexto - IFRN - em sua micro dimensão. Optou-se, assim, pelo desenvolvimento de um estudo de caso de observação (Bogdan; Biklen, 1994), com recurso à administração de um inquérito por questionário aos docentes do IFRN.

No intuito de melhor ilustrar as dimensões e as variáveis mobilizadas apresenta-se, na figura 2, a matriz de análise que orientou a pesquisa empírica. 
Figura 2 -

Dimensões e variáveis de cultura organizacional.

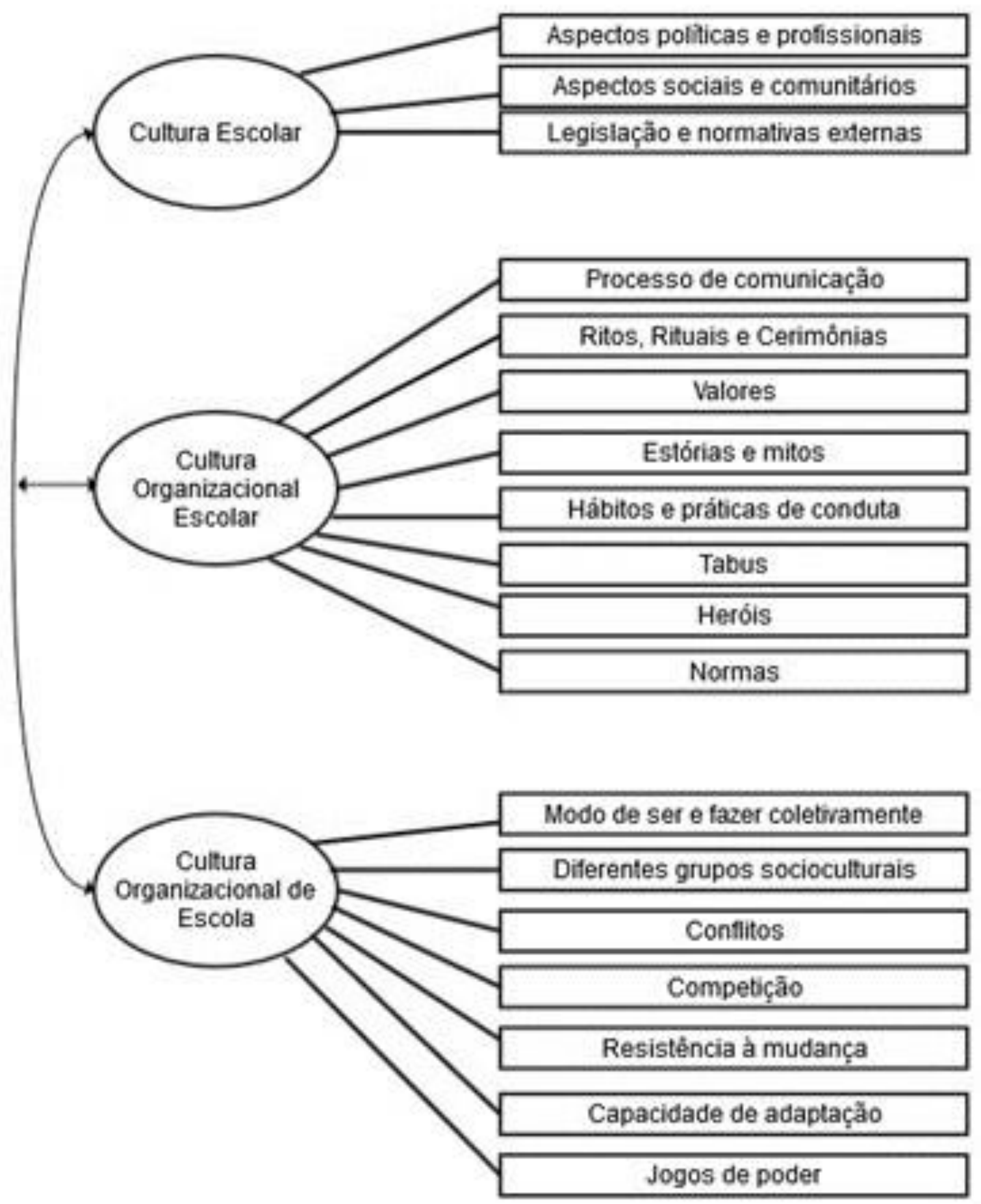

Fonte: a partir de Torres (2013).

Para a administração do instrumento de coleta de dados - o inquérito por questionário - calculou-se a amostra mínima de sujeitos, utilizando-se a fórmula proposta por Cochran (1977), a qual resultou numa necessidade de se conseguir, pelo menos, 205 sujeitos para uma população de 418 docentes, considerando uma expectativa de erro de $5 \%$. 
Por meio de uma amostragem aleatória simples, obteve-se um retorno de 213 questionários, dos quais 176 foram provenientes de docentes do campus Natal/Central Cnat - e 37, de docentes do campus Mossoró.

A justificativa para a escolha desses dois campi está baseada no tempo de existência de ambos. Trata-se dos dois campi mais antigos do IFRN e, por isso mesmo, talvez com uma maior capacidade de avaliar as mudanças culturais, ocorridas na instituição a partir das fases de expansão pela qual vem passando o IFRN.

O questionário estruturado foi previamente testado junto a uma amostra semelhante ao público alvo da investigação. O instrumento final foi formado por 43 questões fechadas, medidas por meio de escalas do tipo Likert com valores rotulados de discordo totalmente até concordo totalmente. O questionário foi administrado de forma online. Um link com o endereço on-line do questionário foi enviado para o e-mail institucional dos docentes e o seu retorno foi aguardado por quatro meses.

Realizou-se uma análise fatorial exploratória, extraída por meio da análise dos componentes principais, e rotação ortogonal Varimax. Quanto aos dados ausentes, optouse pelo critério de substituição dos mesmos pela média. Foi possível observar que, comparativamente ao total de casos, todas as variáveis pesquisadas apresentaram percentuais de dados ausentes, inferiores a $5 \%$.

$\mathrm{Na}$ sequência, procedeu-se à análise de dados extremos univariados a partir da geração de gráficos boxplot, quando foram eliminados dez casos, que demonstraram valores maiores que três cumprimentos da caixa, com base no percentil de $75 \%$. Já no que diz respeito aos valores extremos multivariados, eles foram excluídos da análise levando em consideração a distância de Mahalanobis. Em relação ao nível de significância, foi adotado, para fins deste estudo, um nível de 0,001. Já o número de graus de liberdade foi estimado em 78, com um valor limite obtido para o qui-quadrado de 122,3. Com isso, foram suprimidos quatro casos com valores superiores a tal limite, resultando uma amostra final de 199 casos.

Para realização da AFE, a suposição de normalidade das variáveis estatísticas questões - recorreu à inspeção visual dos gráficos de probabilidade normal dos resíduos. O teste de linearidade foi procedido por meio do cálculo do coeficiente de correlação de Pearson, que eliminou 21 questões que apresentaram valores inferiores ao nível de significância de 0,05. Para verificação da multicolinearidade, foi utilizado o teste Collinearity Diagnostics, por meio do qual eliminou-se uma questão que apresentou valor superior a 0,50 e, ao mesmo tempo, índice de condição superior a 30.

$\mathrm{Na}$ análise da matriz anti-imagem, todas as variáveis observadas na diagonal principal mostraram medidas de adequação da amostra superiores a 0,87. Por fim, a análise das comunalidades resultou na exclusão de 10 variáveis que continham escores de extração inferiores a 0,6, conforme sugerido por Hair et al. (2009).

No que tange à adequação do tamanho da amostra à analise fatorial exploratória, o valor de KMO obtido $(0,874)$ indica que o tamanho da amostra se situa num patamar ótimo. Já em relação à esfericidade, a significância encontrada no teste de Bartlett $(0,0001)$ rejeitou a hipótese nula de que existiriam, na amostra, correlações iguais a 0 (zero). 
Para decidir o número de fatores a serem extraídos pela análise fatorial, optou-se pelo critério da raiz latente. Com ele, verificou-se a formação de três fatores, os quais são apresentados, com suas respectivas cargas fatoriais, no quadro a seguir.

Quadro 1 -

Variáveis observadas do construto cultura organizacional.

\begin{tabular}{|c|c|c|}
\hline Fator & Variáveis observadas & $\begin{array}{l}\text { Cargas } \\
\text { fatoriais }\end{array}$ \\
\hline \multirow[t]{4}{*}{$\begin{array}{l}\text { Imagem } \\
\text { organizacional }\end{array}$} & $\begin{array}{l}\text { Transmite para a população a imagem de uma } \\
\text { Instituição que oferece serviços de qualidade (Q6) }\end{array}$ & ,823 \\
\hline & $\begin{array}{l}\text { Desenvolve suas ações considerando sua } \\
\text { responsabilidade social junto à sociedade (Q5) }\end{array}$ & 813 \\
\hline & $\begin{array}{l}\text { Possui uma boa interação com a comunidade externa } \\
\text { (empresas; órgãos públicos) (Q4) }\end{array}$ & ,696 \\
\hline & Me identifico com a função social do IFRN (Q9) & ,651 \\
\hline \multirow[t]{4}{*}{ Valores e normas } & $\begin{array}{l}\text { Todos os servidores são tratados de forma igualitária, } \\
\text { imparcial e justa (Q26) }\end{array}$ & ,799 \\
\hline & $\begin{array}{l}\text { O processo de ocupação de cargos eletivos é feito de } \\
\text { maneira adequada (Q23) }\end{array}$ & ,750 \\
\hline & $\begin{array}{l}\text { Os processos de trabalho no IFRN são coerentes, } \\
\text { eficazes (Q21) }\end{array}$ & ,770 \\
\hline & Valores e princípios semelhantes aos outros IFs (Q3) & ,615 \\
\hline \multirow[t]{2}{*}{ Rituais } & $\begin{array}{l}\text { São regularmente celebrados os êxitos que o IFRN } \\
\text { alcança (Q13) }\end{array}$ & ,773 \\
\hline & $\begin{array}{l}\text { Promove momentos especiais de comemorações e } \\
\text { atividades sociais e esportivas (Q12) }\end{array}$ & ,860 \\
\hline
\end{tabular}

Fonte: inquérito por questionário administrado junto a 176 docentes do Campus Natal-Central e 37 Campus Mossoró do IFRN.

Constata-se que os percentuais de variância explicada pelo segundo $(11,988 \%)$ e terceiro $(10,022 \%)$ fatores, comparativamente ao primeiro $(46,934 \%)$, sugerem a possibilidade de levar a efeito os indicadores numa perspectiva unidimensional. Apesar disso, com base na consistência teórica dos três fatores formados, optou-se por mantê-los para efeito do presente estudo. Nesse sentido, o primeiro fator engloba quatro indicadores; o segundo fator foi formado por outros quatro indicadores; e o terceiro e último fator foi composto por dois indicadores.

Para avaliar a influência das variáveis do perfil - independentes -, nas variáveis latentes de cultura organizacional - dependentes -, foram estimados modelos de regressão dispostos nas tabelas 1 a 2. Nesse estudo, foi utilizado o método de estimação enter, o qual incorpora ao modelo todas as variáveis.

Para fazer parte do modelo de regressão, algumas das variáveis independentes nominais foram transformadas em variáveis binárias ou dicotômicas - variáveis dummy -, assumindo apenas, um de dois valores: 1 - para indicar a presença de determinada característica; e 0, para os demais casos, conforme descrito a seguir: 
Quadro 2 -

Variáveis dummies.

\begin{tabular}{|c|c|c|c|c|}
\hline $\begin{array}{l}\text { Variável } \\
\text { nominal }\end{array}$ & \multicolumn{4}{|c|}{ Variáveis dummies } \\
\hline Gênero & \multicolumn{4}{|c|}{ Assumiu o valor 1 para o sexo masculino e 0 aos demais casos } \\
\hline $\begin{array}{l}\text { Campus de } \\
\text { lotação }\end{array}$ & \multicolumn{4}{|c|}{ O valor 1 foi relacionado ao campus Natal-Central e 0 aos demais casos } \\
\hline Cargo/função & \multicolumn{2}{|c|}{$\begin{array}{l}\text { A primeira variável assumiu o } \\
\text { valor } 1 \text { para os casos que } \\
\text { ocupavam cargo administrativo }\end{array}$} & \multicolumn{2}{|c|}{$\begin{array}{l}\text { A segunda variável assumiu o valor } 1 \text { para os } \\
\text { casos que foram contratados como efetivos; e } \\
0 \text { para os demais casos }\end{array}$} \\
\hline $\begin{array}{l}\text { Regime de } \\
\text { trabalho }\end{array}$ & \multicolumn{2}{|c|}{$\begin{array}{l}\text { A primeira variável assumiu o } \\
\text { valor } 1 \text { para os casos que } \\
\text { tinham regime de trabalho de } \\
\text { dedicação exclusiva }\end{array}$} & \multicolumn{2}{|c|}{$\begin{array}{l}\text { A segunda variável assumiu o valor } 1 \text { para os } \\
\text { casos que tinham regime de trabalho de } 20 \\
\text { horas semanais }\end{array}$} \\
\hline Titulação ${ }^{2 *}$ & $\begin{array}{l}\text { A primeira variável } \\
\text { assumiu o valor } 1 \\
\text { para os casos que } \\
\text { tinham pós-graduação }\end{array}$ & $\begin{array}{l}\text { A se } \\
\text { assumiu } \\
\text { casos } \\
\text { mestrad }\end{array}$ & $\begin{array}{l}\text { gunda } \\
\text { o valor } 1 \text { pará os } \\
\text { que } \\
\text { linham }\end{array}$ & $\begin{array}{l}\text { A terceira } \text { variável } \\
\text { assumiu o valor } 1 \text { para os } \\
\text { casos que tinham } \\
\text { doutorado }\end{array}$ \\
\hline $\begin{array}{l}\text { Área de } \\
\text { formação }\end{array}$ & \multicolumn{4}{|c|}{$\begin{array}{l}\text { Assumiu o valor } 1 \text { para os casos que tinham formação acadêmica na área das } \\
\text { ciências exatas e } 0 \text { para os demais casos }\end{array}$} \\
\hline $\begin{array}{l}\text { Remanejame } \\
\text { nto }\end{array}$ & \multicolumn{4}{|c|}{$\begin{array}{l}\text { Assumiu o valor } 1 \text { para os casos que já tinham sido remanejados de um campus } \\
\text { para outro }\end{array}$} \\
\hline $\begin{array}{l}\text { Prestação de } \\
\text { serviço }\end{array}$ & \multicolumn{4}{|c|}{$\begin{array}{l}\text { Assumiu o valor } 1 \text { para os casos que já tinham prestado serviços a outras } \\
\text { organizações ao mesmo tempo que desempenhavam suas atividades no IFRN; } \\
\text { e } 0 \text { para os demais casos }\end{array}$} \\
\hline Bolsas & \multicolumn{4}{|c|}{$\begin{array}{l}\text { Assumiu o valor } 1 \text { para os casos que já tinham recebido algum tipo de bolsa } \\
\text { para desempenhar atividades além daquelas realizadas enquanto professor do } \\
\text { IFRN; e } 0 \text { para os demais casos }\end{array}$} \\
\hline
\end{tabular}

Fonte: inquérito por questionário administrado junto a 176 docentes do Campus Natal-Central e 37 Campus Mossoró do IFRN.

Além do estabelecimento do modelo de regressão, também foram desenvolvidos cálculos visando à criação de índices médios de percepção das variáveis latentes, o que gerou novas variáveis ao banco de dados. Para tanto, foi realizado o cálculo da média aritmética simples das variáveis observadas em cada uma das variáveis latentes, criando, assim, as seguintes variáveis dependentes: Média das variáveis observadas de imagem organizacional - Mel -; Média das variáveis observadas de valores e normas - MeV - e Média das variáveis observadas de rituais - MeRit.

\section{Caracterização dos sujeitos da pesquisa}

Quanto à caracterização do perfil socioprofissional dos docentes lotados nos campi alvo deste estudo, serão apresentadas informações em relação a um conjunto diversificado de dimensões de natureza social, profissional e organizacional. Quanto ao gênero, percebeu-se grande predominância de indivíduos do sexo masculino (64\%). Esse mesmo percentual praticamente se repetiu em cada campus separadamente. Tal fato

\footnotetext{
2 Como o objetivo era comparar os grupos que tinham graduação com aqueles que não têm, a categoria base escolhida foi a que representa o grupo de casos com "graduação".
} 
pode ser justificado tanto pelas características dos cursos ofertados que, por se tratarem de cursos com enfoque nas áreas técnicas, não apresentam grande quantitativo de mulheres, conforme discutido por Kuenzer (1991).

Já os dados que tratam do tempo de trabalho como docente do IFRN revelam que pouco mais de $30 \%$ dos docentes estão há menos de dez anos trabalhando na instituição. A metade desses docentes já ingressou na instituição a partir de 2009. Existe um percentual relativamente pequeno de docentes que lecionam na instituição há, aproximadamente, 11 a 15 anos. Esse percentual pode indicar que o período dos primeiros anos do século 21 foi de baixo crescimento institucional. Por fim, destaca-se, ainda, outro percentual significativo de professores que atuam na instituição há mais de 20 anos. Ainda tratando dessa variável, foi verificado que o tempo médio de atuação profissional no campus Mossoró foi de sete anos e meio, enquanto, no campus NatalCentral, esse tempo era de quase 14 anos.

Concernente ao regime de trabalho dos docentes alvo do estudo, tem-se que em torno de $85 \%$ atuam na instituição sob o regime de trabalho de dedicação exclusiva. Isso significa dizer que eles não podem manter vínculo empregatício com nenhum outro empregador ou mesmo ser acionista majoritário em algum tipo de sociedade empresarial. Junto aos demais que não possuem dedicação exclusiva ao IFRN, estão incluídos os contratos de trabalhos dos professores substitutos ou temporários, os quais representam $5 \%$ do grupo de professores aqui estudados.

Tratando dos cargos e funções desenvolvidas pelo professor no IFRN, de forma semelhante ao regime de trabalho, demonstra-se um grande percentual de indivíduos que ocupam o cargo de docente atuando apenas em sala de aula: $77,5 \%$. Desses, $84 \%$ são de professores efetivos. Outros 17\% desempenhavam funções administrativas como, diretor-geral; diretor-acadêmico; diretor de diretorias não acadêmicas; coordenador de curso e coordenador de coordenações não acadêmicas. É válido destacar que, mesmo ocupando funções administrativas, esses docentes não deixam de atuar em sala de aula, exceção feita à função de diretor-geral.

No que tange à titulação dos docentes investigados, identificou-se, que cerca de $84 \%$ dos docentes já concluíram uma pós-graduação stricto sensu, sendo que desses $55 \%$ são mestres e $29 \%$ são doutores. Esses dados indicam que os campi ainda possua uma lacuna para incremento da titulação de seu corpo docente.

O remanejamento consiste na remoção, a pedido do docente, para uma unidade administrativa diferente da que ele esteja lotado. Quanto aos indivíduos participantes da amostra, foi perguntado se eles já haviam sido remanejados em algum momento desde a sua entrada no IFRN. Verificou-se que 35\% deles responderam afirmativamente, o que representa uma significativa rotatividade dos profissionais da instituição.

Percebeu-se, ainda, uma concentração de sujeitos nas faixas etárias intermediárias. Verificou-se que $75 \%$ dos indivíduos tinham acima de 33 anos e desses $52 \%$ possuem idade superior a 42 anos, e outros $12 \%$ possuem idade acima de 58 anos. Esse último valor está associado ao percentual de docentes que trabalham na instituição há mais de 25 anos e pode representar aqueles que são conhecedores das manifestações culturais mais antigas do IFRN sendo, por isso, possíveis transmissores de uma cultura que vai se 
transformando à medida que novos docentes ingressam na instituição. Essa diferenciação na idade e, por consequência, no tempo de trabalho no IFRN, tem implicações na remuneração dos docentes.

Verificou-se que existe a distribuição de um quantitativo maior de docentes em duas faixas de remuneração, com uma concentração no recebimento de vencimentos acima de $R \$ 5.000,00$ até $R \$ 15.000,00$ (67\%). Aproximadamente, um quarto dos docentes faz jus a vencimentos superiores a $R \$ 15.000,00$, enquanto $16 \%$ recebem até $R \$ 5.000,00$. A remuneração média entre os docentes pesquisados é de $R \$ 10.813,72$, com variação entre $R \$ 2.173,85$ e $R \$ 26.611,94$ e está bem acima do piso salarial nacional definido pelo governo.

Ainda é válido comentar que, no final do ano de 2014, foi atrelado à remuneração dos docentes o reconhecimento de saberes e competências - RSC. A implementação dessa ação permitiu que os professores pudessem receber uma retribuição por titulação RT - equivalente ao nível de carreira seguinte ao de sua titulação. Com isso, boa parte dos docentes recebeu um incremento próximo a $40 \%$ de seus vencimentos.

Verificou-se certa concentração de profissionais com formação em Engenharia. Registrou-se, ainda, que grande parte dos profissionais classificados como tendo formação nas ciências tecnológicas, concluíram cursos voltadas para a área de informática. Esse resultado é influenciado pelo tipo de formação que os IFs propõem oferecer à sociedade, conforme descrito em Pacheco (2011). Merecem destaque as Ciências Sociais Aplicadas, na qual preponderam formação voltada para a área de gestão: Administração, Ciências Contábeis e Economia.

Verificou-se que $75 \%$ da amostra possuía uma carga horária de até 16 horas semanais em sala de aula, sendo a mediana de 14 horas. Ademais, foi constatado, por meio da mediana, que os professores possuíam até quatro turmas, sendo que os percentis apontam que $75 \%$ dos respondentes possuíam até cinco turmas. Essas turmas dividiam-se entre os cursos de nível médio/técnico e superior. Tais turmas possuíam, em sua maior parte, 37 alunos para os cursos técnicos e 25 alunos para os cursos superiores, o que implicaria um quantitativo semestral de alunos por professor variando entre $125 \mathrm{e}$ 185.

\section{Identificando microcampos docentes}

Inicialmente, fez-se uma análise técnico-estatística dos modelos de regressão, procedendo um registro mais descritivo para, em seguida, serem realizadas interpretações dos dados, de maneira a se obter conclusões parciais acerca das relações de influências entre as variáveis mencionadas no parágrafo anterior e as variáveis do perfil, conforme pode ser visto na sequência.

Dessa forma, serão apresentados os modelos que tratam das variáveis dependentes criadas a partir das variáveis de cultura organizacional. $\mathrm{O}$ primeiro deles se refere à imagem organizacional - Mel. 
Tabela 1 -

Modelo de regressão Mel e Mel-Reespecificado.

\begin{tabular}{|c|c|c|c|c|c|c|}
\hline \multirow[t]{2}{*}{ Variáveis Independentes } & \multicolumn{3}{|c|}{ Mel } & \multicolumn{3}{|c|}{ Mel-Reespecificado } \\
\hline & Beta & Sig. & VIF & Beta & Sig. & VIF \\
\hline (Constante) & & ,012 & & & 011 & \\
\hline Ano de nascimento &,- 253 & ,028 & 2,876 &,- 255 & ,027 & 2,874 \\
\hline Tempo de trabalho &,- 216 & 079 & 3,303 &,- 218 & ,075 & 3,293 \\
\hline Remuneração &,- 067 &, 553 & 2,807 &,- 038 & ,714 & 2,418 \\
\hline Carga horária &,- 031 & ,694 & 1,396 &,- 031 & ,697 & 1,396 \\
\hline Quant. Turmas & 019 & ,807 & 1,385 & 017 & ,828 & 1,383 \\
\hline Quant. Alunos cursos técnicos & , 108 & ,153 & 1,234 & ,092 & , 197 & 1,111 \\
\hline Quant. Alunos cursos superiores & ,016 & ,824 & 1,184 & 017 & 820 & 1,182 \\
\hline Sexo* &,- 099 & ,189 & 1,237 &,- 107 & , 146 & 1,202 \\
\hline Campus de lotação* &,- 200 & ,011 & 1,327 &,- 195 &, 012 & 1,315 \\
\hline Cargo com função adm. $x$ sem função adm. ${ }^{*}$ & ,160 & ,028 & 1,141 & ,158 & ,028 & 1,140 \\
\hline Prof. efetivo $x$ substituto* & ,088 & ,417 & 2,602 & ,082 & ,447 & 2,565 \\
\hline Regime DE x sem DE* &,- 018 & ,897 & 4,141 &,- 030 & ,826 & 4,044 \\
\hline Regime $20 \mathrm{~h} \times$ sem $20 \mathrm{~h}^{*}$ &,- 092 & ,398 & 2,600 &,- 094 & ,384 & 2,588 \\
\hline Graduação x Pós grad.* &, 117 & ,453 & 5,310 & ,035 & ,648 & 1,281 \\
\hline Graduação x Mestrado* & 130 &, 564 & 11,108 & & & \\
\hline Graduação x Doutorado* & ,147 &, 504 & 10,634 & & & \\
\hline Área de Formação Exatas x Humanas* &,- 118 & ,142 & 1,409 &,- 128 & ,102 & 1,346 \\
\hline Remanejamento* $^{*}$ &,- 120 & ,118 & 1,293 &,- 114 & ,134 & 1,275 \\
\hline Prestação de Serviços* ${ }^{*}$ & ,102 & ,184 & 1,276 & 103 & 174 & 1,272 \\
\hline Bolsa* $^{*}$ & 099 & 207 & 1,348 & ,090 & 242 & 1,308 \\
\hline R2 ajustado & , 100 & & & ,107 & & \\
\hline Teste F & 006 & & &, 003 & & \\
\hline Sig. & ,050 & & & ,060 & & \\
\hline DW & 2,217 & & & 2,228 & & \\
\hline White & ,385 & & & ,296 & & \\
\hline
\end{tabular}

*Variáveis dummies

Fonte: inquérito por questionário administrado junto a 176 docentes do campus Natal-Central e 37 campus Mossoró do IFRN.

Com base na análise de regressão linear múltipla, efetivada entre as variáveis independentes - dados do perfil - e a variável dependente - imagem organizacional exposta na tabela anterior, constatou-se que o modelo testado é expressivo, uma vez que, pela análise de variância, os valores encontrados para 0 Teste $F$ foram estatisticamente significativos. A verificação da autocorrelação, da normalidade, da homocedasticidade e da multicolinearidade do modelo são apresentadas na tabela anterior, mediante testes de Durbin Watson (DW), Kolmogorov-Smirnov (KS), White e dos Fatores de inflação de variância (VIF). Todos os escores apresentaram valores adequados, com exceção da multicolinearidade para as variáveis 'graduação x mestrado' e 'graduação x doutorado', tendo em vista que os valores obtidos para elas foram superiores a 10. Tal situação sugere a retirada dessas variáveis do modelo.

A reespecificação do modelo feita visando retirar as variáveis com multicolinearidade e, ao mesmo tempo, verificar, novamente, a normalidade dos dados, verificou uma \begin{tabular}{|l|l|l|l|l|l|}
\hline Regae: Rev. Gest. Aval. Educ. & Santa Maria & v. 11 & n. 20 & e68214, p. 1-27 & 2022 \\
\hline
\end{tabular} 
melhora no percentual explicativo do modelo de $10 \%$ para $10,7 \%$ e, ao mesmo tempo, a não rejeição da hipótese de normalidade dos dados $(K S=0,06)$. As variáveis que contribuíram de maneira mais significativa foram: idade do respondente; campus de lotação e o fato de ocupar, ou não, um cargo na gestão do IFRN. Outra variável apresentou valor significativo (90\%) como foi o caso do tempo de trabalho na instituição.

$\mathrm{Na}$ sequência, têm-se as discussões sobre o modelo que trata da variável 'valores e normas - MeV - como variável dependente.

Tabela 2 -

Modelo de regressão MeV e MeV-Reespecificado.

\begin{tabular}{|c|c|c|c|c|c|c|}
\hline Variáveis independentes & & $\mathrm{Mel}$ & & $\mathrm{MeV}-$ & Reesp & cificado \\
\hline & Beta & Sig. & VIF & Beta & Sig. & VIF \\
\hline (Constante) & & ,003 & & &, 002 & \\
\hline Ano de nascimento &,- 322 & ,005 & 2,876 &,- 324 &, 004 & 2,874 \\
\hline Tempo de trabalho &,- 237 & ,052 & 3,303 &,- 238 & ,050 & 3,293 \\
\hline Remuneração & 072 &, 520 & 2,807 & ,115 & ,266 & 2,418 \\
\hline Carga horária &,- 120 &, 130 & 1,396 &,- 119 &, 131 & 1,396 \\
\hline Quant. Turmas & ,137 & 082 & 1,385 & 133 & ,089 & 1,383 \\
\hline Quant. Alunos cursos técnicos & ,107 & ,151 & 1,234 & 082 & ,243 & 1,111 \\
\hline Quant. Alunos cursos superiores & ,106 & , 147 & 1,184 & ,107 &, 142 & 1,182 \\
\hline Sexo* &,- 051 & ,490 & 1,237 &,- 063 & ,385 & 1,202 \\
\hline Campus de lotação* &,- 217 & ,005 & 1,327 &,- 209 & ,007 & 1,315 \\
\hline Cargo com função adm. $x$ sem função adm. * & 175 & ,015 & 1,141 & ,173 & ,016 & 1,140 \\
\hline Prof. efetivo x substituto* & ,139 & , 197 & 2,602 &, 131 & ,221 & 2,565 \\
\hline Regime DE x sem DE* &,- 136 & ,317 & 4,141 &,- 152 & ,256 & 4,044 \\
\hline Regime $20 \mathrm{~h}$ x sem $20 \mathrm{~h}^{*}$ &,- 133 & ,217 & 2,600 &,- 135 & ,207 & 2,588 \\
\hline Graduação x Pós grad. * & ,164 & ,288 & 5,310 & 051 & ,499 & 1,281 \\
\hline Graduação x Mestrado* & ,175 & ,432 & 11,108 & & & \\
\hline Graduação x Doutorado* & ,214 & ,326 & 10,634 & & & \\
\hline Área de Formação Exatas x Humanas* & ,123 & ,122 & 1,409 & ,109 & , 158 & 1,346 \\
\hline Remanejamento* $^{*}$ &,- 093 & ,219 & 1,293 &,- 084 & ,265 & 1,275 \\
\hline Prestação de Serviços* $^{*}$ & ,145 & 056 & 1,276 & ,147 & ,051 & 1,272 \\
\hline Bolsa* $^{*}$ & 085 & ,273 & 1,348 & 072 & ,345 & 1,308 \\
\hline R2 ajustado & & & & ,126 & & \\
\hline Teste F & & & & 001 & & \\
\hline ,100 & & & & ,150 & & \\
\hline 2,053 & & & & 2,05 & & \\
\hline White & & & & ,299 & & \\
\hline
\end{tabular}

* Variáveis dummies

Fonte: inquérito por questionário administrado junto a 176 docentes do Campus Natal-Central e 37 Campus Mossoró do IFRN.

A maior parte das suposições foi atendida de maneira semelhante aos modelos anteriores. Para esse modelo, especificamente, a diferença em relação aos anteriores foi percebida no teste de White, que verifica a homocedasticidade das variáveis do modelo. O teste foi significante - nível de 1\% -, o que sugere a rejeição da hipótese nula de que os dados são homocedásticos. 
A reespecificação do modelo foi feita com o propósito de retirar as variáveis com multicolinearidade e, ao mesmo tempo, verificar, novamente, a homocedasticidade. Percebeu-se, portanto, que a exclusão das variáveis com multicolinearidade permitiu o atendimento ao pressuposto de uma distribuição homogênea dos dados - teste de White = 0,299 - e, também, um pequeno aumento no percentual explicativo do modelo de $12,2 \%$ para $12,6 \%$. As variáveis que contribuíram de maneira mais significativa para o modelo foram: idade do respondente; tempo de trabalho na instituição; campus de lotação e o fato de ocupar, ou não, um cargo na gestão do IFRN. Duas outras variáveis apresentaram valor significativo (90\%): quantidade de turmas e o fato de prestar, ou não, serviços a outras instituições ao mesmo tempo que trabalha no IFRN.

Por fim, a seguir, têm-se as discussões sobre o modelo que aborda a variável 'Rituais' - MeRit - como variável dependente.

Tabela 3 -

Modelo de regressão MeRit e MeRit-Reespecificado.

\begin{tabular}{|c|c|c|c|c|c|c|}
\hline \multirow[t]{2}{*}{ Variáveis independentes } & \multicolumn{3}{|c|}{ MeRit } & \multicolumn{3}{|c|}{$\begin{array}{c}\text { MeRit- } \\
\text { Reespecificado }\end{array}$} \\
\hline & Beta & Sig. & VIF & Beta & Sig. & VIF \\
\hline (Constante) & & ,004 & & & 003 & \\
\hline Ano de nascimento & $\begin{array}{l}-314 \\
\end{array}$ & ,007 & 2,876 &,- 317 & ,007 & 2,874 \\
\hline Tempo de trabalho &,- 314 & ,012 & 3,303 &,- 320 & ,011 & 3,293 \\
\hline Remuneração & 015 & ,895 & 2,807 & 080 & ,454 & 2,418 \\
\hline Carga horária &,- 067 & ,407 & 1,396 &,- 065 & ,418 & 1,396 \\
\hline Quant. Turmas & ,083 & 304 & 1,385 & ,078 & ,333 & 1,383 \\
\hline Quant. Alunos cursos técnicos & ,018 & ,811 & 1,234 &,- 016 & ,825 & 1,111 \\
\hline Quant. Alunos cursos superiores & 110 & 140 & 1,184 & 109 & 142 & 1,182 \\
\hline Sexo* &,- 020 & ,794 & 1,237 &,- 039 & ,598 & 1,202 \\
\hline Campus de lotação* &,- 235 & ,003 & 1,327 &,- 224 & 005 & 1,315 \\
\hline Cargo com função adm. x sem função adm. * & 171 & ,020 & 1,141 & 168 & ,022 & 1,140 \\
\hline Prof. efetivo $x$ substituto* & 060 & ,586 & 2,602 & ,042 & 698 & 2,565 \\
\hline Regime DE x sem DE* &,- 264 & ,058 & 4,141 &,- 295 & ,033 & 4,044 \\
\hline Regime 20h x sem 20h* &,- 111 & ,313 & 2,600 &,- 118 & ,283 & 2,588 \\
\hline Graduação x Pós grad. ${ }^{*}$ & , 165 & ,294 & 5,310 &,- 039 & ,616 & 1,281 \\
\hline Graduação x mestrado* & ,329 & , 148 & 11,108 & & & \\
\hline Graduação x doutorado* & ,345 & ,122 & 10,634 & & & \\
\hline Área de formação exatas $x$ humanas* & ,036 & ,656 & 1,409 & ,011 & ,890 & 1,346 \\
\hline Remanejamento* & 052 & ,506 & 1,293 & 065 & ,400 & 1,275 \\
\hline Prestação de serviços* & 051 &, 510 & 1,276 & 056 & ,467 & 1,272 \\
\hline Bolsa* $^{*}$ & 051 & ,522 & 1,348 & ,030 & 704 & 1,308 \\
\hline R2 ajustado & ,082 & & &, 080 & & \\
\hline Teste F & ,016 & & & ,014 & & \\
\hline $\mathrm{KS}$ & ,120 & & & ,030 & & \\
\hline DW & 1,872 & & & 1,883 & & \\
\hline White & 627 & & & 266 & & \\
\hline
\end{tabular}

*Variáveis dummies

Fonte: inquérito por questionário administrado junto a 176 docentes do campus Natal-Central e 37 campus Mossoró do IFRN. 
Esse modelo apresentou-se significante, com resíduos numa distribuição normal e homocedásticos e sem autocorrelação entre variáveis. As variáveis com multicolinearidade foram as mesmas presentes em todos os modelos anteriores, o que sugere algum erro na especificação dessa variável dummy. A reespecificação do modelo foi feita para retirar as variáveis com multicolinearidade, e um fato novo ocorreu nesse modelo após a retirada das variáveis que possuíam multicolinearidade, já que houve uma diminuição do poder explicativo do modelo - de 8,2\% para $8 \%$. Além disso, o modelo deixou de apresentar uma distribuição normal de seus resíduos ( $K S=0,030)$. Para uma verificação da normalidade da distribuição dos resíduos, utilizou-se, também, a análise da Figura 3, exposta a seguir, conforme indicado por Tabachnick e Fidell (1989). A intenção era associar a análise do gráfico com o resultado do teste estatístico para confirmação do descarte, ou não, do modelo.

Figura 3 -

P-P Plot para análise da normalidade dos resíduos.

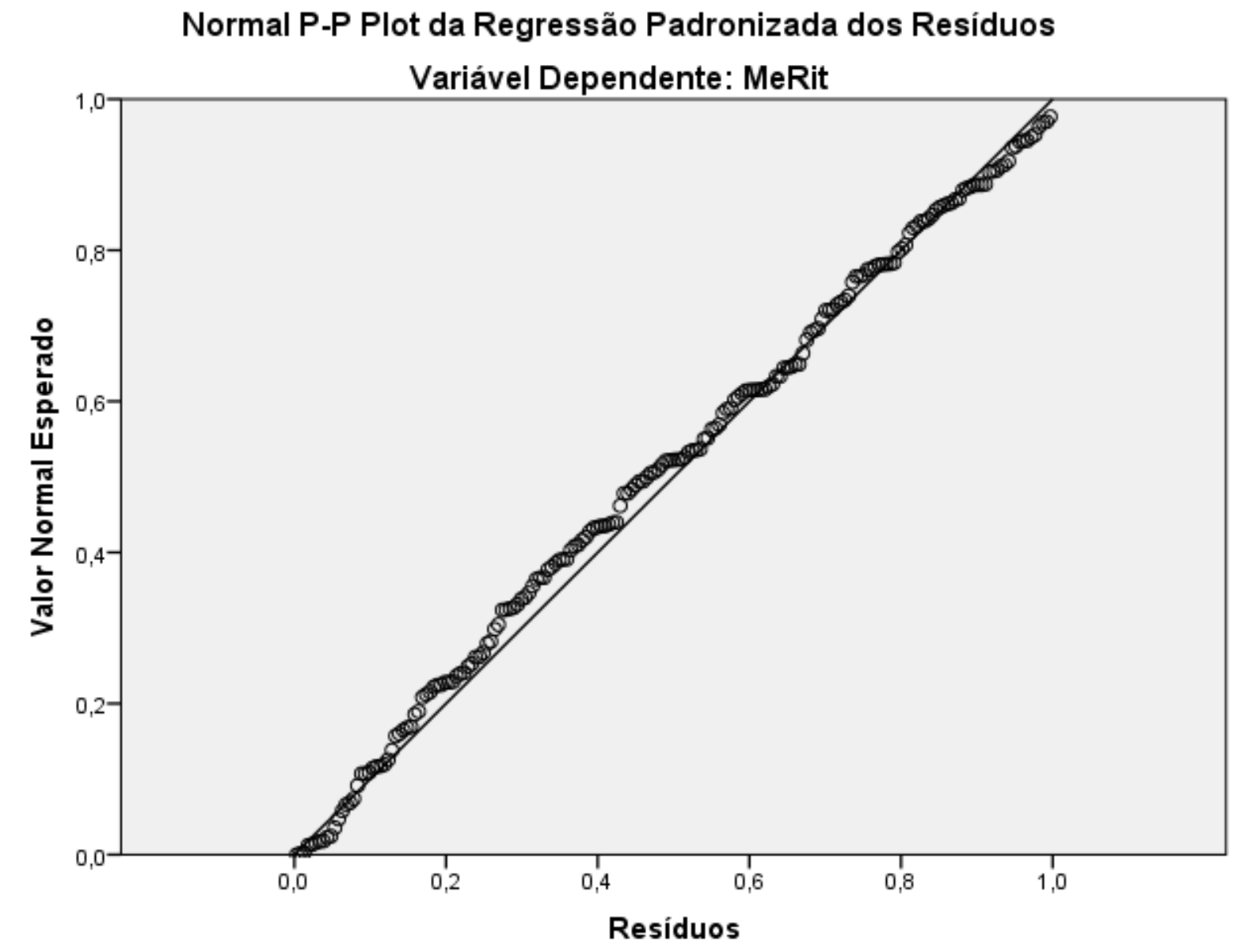

Fonte: inquérito por questionário administrado junto a 176 docentes do campus Natal-Central e 37 campus Mossoró do IFRN.

Com base na análise do gráfico anterior, e considerando as características do estudo e dos dados aqui utilizados, além do leve desvio da curtose observado, optou-se pela manutenção dos valores originais da variável. 
Por fim, após a exclusão das variáveis com multicolinearidade, verificou-se o atendimento ao pressuposto de uma distribuição homogênea dos dados, de ausência de autocorrelação e de homocedasticidade. As variáveis que contribuíram de maneira mais significativa para o modelo foram as mesmas do modelo anterior - idade do respondente; tempo de trabalho na instituição; campus de lotação e o fato de ocupar, ou não, um cargo na gestão do IFRN - e mais o fato do sujeito possuir, ou não, um regime de trabalho de dedicação exclusiva.

\section{As (sub)culturas docentes no contexto da cultura organizacional plural}

Agora, de forma a proceder uma análise mais reflexiva acerca dos modelos de regressão anteriormente apresentados, tem-se que as variáveis independentes - dados do perfil - que influenciavam as dependentes - variáveis de cultura organizacional - foram praticamente idênticas: idade do respondente; tempo de trabalho na instituição; campus de lotação e o fato de ocupar, ou não, um cargo na gestão do IFRN. Além dessas, após a reespecificação dos modelos, a variável que trata do fato de o professor possuir ou não o regime de trabalho de dedicação exclusiva; e a variável que abordava o fato de o docente possuir, ou não, o título de graduado, também passaram a ser variáveis de influência.

Apesar da nomenclatura aqui utilizada - variável dependente e independente -, não se tinha em mente discutir a natureza ontológica da cultura numa perspectiva apenas funcionalista, como uma importação externa à organização, ou como um fator endógeno e idiossincrático dela. Diferente disso, considerou-se a cultura, também, como um processo contínuo de construção e reconstrução, por meio das relações sociais. Procurou-se, portanto, realizar análises que partissem, não apenas de uma representação de atores organizacionais simplesmente limitados a um espaço de trabalho, numa perspectiva física, mas como um grupo potencialmente gerador de uma (sub)cultura, que tem, de maneira compartilhada, uma mesma visão de mundo. Em relação a esse grau de partilha por parte dos atores organizacionais, e partindo dos pressupostos teóricos de Martin (1992), recorreu-se a três possíveis tipos ideais para a problemática da cultura organizacional: o integrador, o diferenciador e o fragmentador. Por serem considerados tipos ideais, partiu-se da suposição de que uma abordagem sociológica e organizacional se torna incompleta quando orientada por uma única perspectiva, de maneira que se acredita que existe uma predominância, mas, também, uma complementariedade entre esses tipos, o que seria relevante para a compreensão dos fenômenos em estudo, abordado nas análises seguintes.

Partindo para a análise variável a variável, tem-se que a variável independente 'ano de nascimento' apresentou coeficiente beta negativo para todas as variáveis dependentes. Isso significa dizer que, quanto menor o ano de nascimento - docentes com maior idade -, melhor a avaliação que foi feita das variáveis de imagem organizacional, valores e normas, e rituais. Ou seja, os professores mais jovens possuíam uma percepção mais crítica referente às manifestações culturais. Um comentário que merece registro acerca dessa variável independente é que ela apresentou os maiores coeficientes beta padronizados em todas as variáveis dependentes, o que pode indicar que a idade do professor é a variável mais relevante para as relações aqui estabelecidas. E considerando o entendimento de Hargreaves (1998) de que a cultura docente se constitui numa totalidade composta de diversos microcampos, depreende-se que a idade docente é um 
microcampo docente que influencia a percepção que os docentes têm de sua cultura organizacional. Ou seja, a trajetória de socialização na organização escolar condiciona o modo como os docentes percepcionam a cultura organizacional, desde logo devido ao fato de estes atores se sentirem co-construtores da cultura da instituição.

Infere-se, ainda, que o microcampo docente representado pela idade dos professores, pode envolver diferentes (sub)culturas: professores mais jovens e professores com mais idade, por exemplo. Essas (sub)culturas estariam em conflito, ou discordância, em relação a diversos aspectos da realidade organizacional. A coexistência simultânea de diferentes (sub)culturas, que leva ao dissenso, ou ao antagonismo cultural, são características de manifestações culturais diferenciadoras. A identificação e análise dessas (sub)culturas necessitaria da utilização de lentes microscópicas que permitissem uma visão mais profunda da realidade organizacional.

É por referência a este tipo de manifestação cultural que se perspectiva a influência da proposta de expansão da educação profissional no Brasil que, ao criar novos campi e cursos para os IFs, necessitou aumentar seu corpo docente de forma rápida, tendo em vista os imperativos quantitativos da expansão. A contratação desses novos professores, com perfil relativamente jovem trouxe para o IFRN profissionais que, além de jovens, possivelmente não tinham amplo conhecimento sobre a forma de funcionamento da educação profissional. Ao mesmo tempo, a instituição dispunha de um quadro de profissionais que estavam, há muito tempo, como professores da educação profissional e que haviam passado pelas várias alterações de institucionalidade do IFRN. Esse cenário de diferenciações sociais e culturais, provavelmente, contribui para a existência de inconsistências na intercepção dessas diferentes (sub)culturas, no que tange a imagem, aos valores e normas e aos rituais organizacionais, existindo uma possível imposição e, ao mesmo, uma resistência a um padrão cultural dominante então existente.

Já a variável 'cargo com função administrativa x cargo sem função administrativa' apresentou uma relação de influência significativa e positiva junto aos indicadores de Imagem organizacional, de Valores e normas e de Rituais. E, a partir dos modelos de regressão constantes nas tabelas anteriores, percebeu-se que o microcampo docente formado pelos professores que ocupam cargo de gestão tende a melhor avaliar as variáveis citadas anteriormente. Tal ocorrência pode ser explicada pelo fato de que, ao ocupar um cargo na gestão da instituição, o professor tem a clareza de que não deve criticar a estrutura da qual ele faz parte enquanto gestor. Percebe-se, aqui, um antagonismo existente, em algumas situações, na relação chefe-subordinado, como é o caso da relação diretor acadêmico e professor. Talvez, para os ocupantes da função diretor acadêmico, exista um conflito intrapessoal, isto é, o professor que desempenha a função de diretor acadêmico se percebe diante de um cenário perante o qual tem dúvidas se deveria defender os interesses do seu grupo de origem - e para o qual retornará -, ou se deveria defender os interesses institucionais e da função para a qual foi escolhido. Trata-se, pois, de uma situação ambígua e complexa, que reflete expectativas difusas e que não parece ter solução satisfatória, como ocorre em manifestações culturais fragmentadoras.

A variável 'campus de lotação' também foi significante para a explicação de todas as variáveis de cultura organizacional. Por se tratar de uma variável dummy em que o valor 1 foi atribuído aos docentes lotados no campus Natal-Central (CNAT), os coeficientes \begin{tabular}{|l|l|l|l|l|l|}
\hline Regae: Rev. Gest. Aval. Educ. & Santa Maria & v. 11 & n. 20 & e68214, p. 1-27 & 2022 \\
\hline
\end{tabular} 
beta negativos indicam que o microcampo, formado pelos professores lotados no campus Mossoró (MO), tende a apresentar melhores percepções acerca das variáveis de cultura organizacional. Enfatiza-se, nesse ponto, que o campus Mossosó possui, apenas, uma diretoria acadêmica - unidade organizacional de lotação dos professores -, enquanto o campus Natal-Central possui cinco.

Com base nas discussões até então realizadas, é possível crer que cada diretoria acadêmica pode representar uma (sub)cultura, pelo menos. Assim, justifica-se uma maior heterogeneidade de percepções acerca das variáveis de cultura organizacional no CNAT, a partir de um maior número de (sub)culturas referentes a cada uma das diretorias acadêmicas, conforme classificação discutida por Martin e Frost (2001). Considerando, pois, que cada campus representa um espaço de mediação entre a periferia escolar e o centro político-administrativo, é possível entender as (sub)culturas, contidas dentro do microcampo docente 'campus', como responsável por julgamentos e interpretações, por vezes discordantes, das orientações provenientes dos órgãos centrais do governo. Quanto a essas discordâncias, o CNAT apresentou-se de maneira mais crítica, provavelmente, por se tratar de um campus mais antigo e com professores com maior idade, diferentemente do campus Mossoró que, por apresentar maior rotatividade docente, acaba por possuir professores mais jovens e sem tanto conhecimento acerca dos modos de funcionamento - formal e informal - da organização.

Outra variável independente que também mostrou um poder de influência significante em relação às três variáveis dependentes foi o 'tempo de trabalho do professor no IFRN', medido em anos. Essa variável mostrou uma relação positiva com as variáveis de valores e normas e de rituais. Tem-se, portanto, destaque para o microcampo dos docentes com maior tempo de trabalho no IFRN e que apresentou melhor avaliação quanto às condições oferecidas pela instituição para realizar diferentes atividades, assim como melhor foi a percepção quanto aos princípios e coerência dos processos de trabalho e dos momentos de integração e socialização promovidos pelo IFRN. Acredita-se que esse microcampo está diretamente relacionado ao microcampo 'idade do docente', visto que, na maior parte dos casos, o docente com maior tempo de trabalho também terá maior idade e, por isso, apresentam julgamentos e percepções semelhantes. Tal fato reforça o entendimento de que um professor pode fazer parte de mais de um microcampo ou (sub)cultura, ao mesmo tempo. O que pode justificar esse resultado é que os professores com mais tempo de trabalho vivenciaram momentos nos quais a instituição correu o risco de ser extinta ou passou anos sem recursos suficientes para sua manutenção, de maneira que o cenário atual se apresenta bem mais favorável.

Ainda com relação ao regime de trabalho, a questão de 'possuir, ou não, regime de trabalho de dedicação exclusiva' também surgiu como estatisticamente significante junto ao modelo que abordava os rituais organizacionais. Como o coeficiente de regressão dessa variável foi negativo, pode-se dizer que o microcampo a que pertencem os docentes com DE apresenta uma percepção mais crítica no que tange à oferta de momentos de comemoração e atividades sociais e esportivas por parte do IFRN. Tal percepção crítica pode ser influenciada pelo momento de expansão institucional, pois a 
expansão acarretou a ampliação do quadro de professores e, por consequência, certa heterogeneidade que pode refletir em perda de coesão grupal presente, por exemplo, em momentos de celebração dos êxitos da organização, ou em atividades sociais e esportivas.

Por fim, a partir de Riley (1983), objetivou-se realizar uma observação da cultura existente no contexto organizacional a partir de um ponto de vista plural, no qual coexistem diferentes (sub)culturas. Assim, verificou-se a existência de diversos microcampos docentes associados às diferentes características do perfil dos professores pesquisados, consoante proposição de Hargreaves (1998). Esses microcampos, ainda segundo o autor, são espaços onde circulam saberes e códigos próprios afetos ao grupo.

Os microcampos ou subculturas docentes aqui identificados conseguem explicar, no máximo, $15 \%$ das variáveis de cultura organizacional, sendo os modelos utilizados para essa mensuração considerados significativos. Chega-se à constatação, portanto, de que esses microcampos influenciam a percepção acerca da cultura organizacional, no entanto, existem outras variáveis não identificadas pelo presente estudo, também capazes de influenciar os construtos aqui estudados.

Os resultados obtidos corroboram os encontrados por Tenti Fanfani (2007). O autor apresenta a tese da falta de homogeneidade da cultura docente associada a uma ruptura da coesão interna do corpo docente das instituições. Além disso, para Pérez Gómez (2001) as culturas docentes se inserem e, ao mesmo tempo, influem a cultura organizacional escolar enquanto construtoras da imagem organizacional e possuidoras de valores, normas e rituais que determinam o que um grupo social específico considera valioso em seu contexto profissional. De outra forma, uma cultura docente também será resultante de pressões externas, por processos de socialização de seus integrantes, entre outros fatores. Esse cenário retoma a discussão sobre a perspectiva da cultura enquanto instituinte e instituída (Teixeira, 2000). Nesse sentido, a cultura não pode ser considerada produto absoluto de padrões de comportamento, como não deriva também apenas de aspectos individuais. Ela envolve um "processo contínuo e ativo de construção e reconstrução da realidade através do qual as pessoas criam e recriam o mundo em que vivem" (Teixeira, 2000, p. 9).

Partindo das análises até então realizadas, crê-se que é possível tratar os microcampos docentes de forma semelhante ao entendimento de (sub)cultura, conforme posto por Van Maanen e Barley (1983):

Um conjunto de membros de uma organização que interagem entre si regularmente, se auto-identificam como um grupo distinto dentro da organização, partilham um conjunto de problemas comumente definidos como os problemas de todos e rotineiramente agem com base numa série de representações próprias do grupo. (p. 35)

Assim, acredita-se que, entre os professores do IFRN, não há uma cultura única, mas uma cultura heterogênea, diversificada, composta por várias (sub)culturas que, por vezes, podem estar em conflito quanto aos seus interesses. Pode-se dizer, portanto, que a cultura docente, no caso em estudo, se manifesta como uma cultura diferenciadora, caracterizada pela existência de (sub)culturas em conflito, que irão aparecer num contexto particular. Esse conflito de (sub)culturas foi demonstrado nas análises anteriores, uma vez 
que, para se destacar a influência de um certo grupo de professores procedeu-se uma comparação com outro grupo - por exemplo, professores jovens e professores com maior idade.

Também supõe-se ser possível vislumbrar a presença de manifestações culturais fragmentadoras, partindo do pressuposto que os docentes apresentam problemas e interesses diversos, e que esses podem ser compartilhados com diferentes grupos, fazendo com que o professor, de maneira ambígua, procure fazer parte de diferentes grupos, compartilhando valores e crenças que, num dado momento, atendem aos seus interesses.

Desta abordagem de (sub)culturas defende-se, pois, a pluralidade cultural existente no interior da organização. Tal fato não significa dizer que todas as culturas existentes no interior da organização são importantes, haja vista que podem existir umas mais influentes que outras, mas também não quer dizer que exista uma relação de subordinação de uma (sub)cultura em relação a uma cultura maior. Por isso, a utilização do prefixo 'sub' entre parêntesis. Acredita-se que a cultura organizacional seria formada pela junção de algumas (sub)culturas, mas essas não estarão submissas a primeira, podendo até se portar como um contra-cultura.

Segundo entendimento de Torres (2004), o IFRN pode ser considerado um espaço intenso de produção cultural, de interação social e de trocas simbólicas, constantemente influenciado pela rotatividade de um número considerável de professores, e sujeito a uma multiplicidade de condicionamentos externos provenientes da administração central, da comunidade e de fatores internos derivados do conflito e das relações diferenciadas entre os atores escolares e educativos. Ou seja, o IFRN, em virtude de suas diferentes manifestações culturais, é um espaço de sínteses culturais constantemente reatualizadas.

\section{Considerações finais}

As manifestações da cultura organizacional foram analisadas a partir de três fatores, sugeridos pela análise fatorial exploratória: imagem organizacional; valores e normas e rituais.

A partir dos resultados obtidos, o que foi revelado acerca da Imagem organizacional que envolvia os docentes dos dois campi do IFRN abordava uma dimensão comunitária, a qual está circunscrita à boa imagem externa que a instituição possuía junto à sociedade, em virtude do que a primeira oferece para a segunda, e as ações de responsabilidade social desenvolvidas pela instituição.

O fator Valores e normas estaria inserido na dimensão nomeada por Torres (2004) de dimensão organizacional, e envolvia os aspectos formais internos à instituição. Esses aspectos formais internos, que tratavam do igualitarismo, dos processos de trabalho e da ocupação de cargos eletivos, eram percebidos pelos docentes como inconsistentes. Por fim, o fator Rituais estaria inserido na dimensão de sociabilidade, a qual se remete aos aspectos informais, presentes no interior da organização. Esses aspectos, segundo percepção dos docentes, estão manifestos nas celebrações de êxitos e nos eventos sociais e esportivos, organizados pelos servidores. 
Além disso, as variáveis do perfil socioprofissional que influenciavam os fatores da cultura na instituição foram praticamente as mesmas: idade do respondente; tempo de trabalho na instituição; campus de lotação; ocupar, ou não, um cargo na gestão do IFRN e possuir, ou não, o regime de trabalho de dedicação exclusiva.

A relação de influência das variáveis do perfil socioprofissional dos docentes com os fatores de cultura organizacional foi analisada com o objetivo de identificar a predominância de microcampos docentes (Hargreaves, 1998) no seio da organização em estudo. $O$ que se pode averiguar foi a existência de diversos microcampos - subculturas. Um deles era formado pela idade dos docentes, uma vez que a variável 'ano de $n$ nascimento' se apresentou como influenciadora de todas os fatores de cultura organizacional. $O$ destaque para esse microcampo, como o mais influente entre aqueles identificados pelo presente estudo, indica a atuação dos professores com maior idade na tentativa de manter traços culturais historicamente enraizados, isto é, esses docentes representariam os guardiões de uma cultura instituída.

Outro microcampo, aparentemente influenciador nos modos de ser e agir da instituição estudada, foi aquele formado pelos indivíduos que ocupam cargos de gestão, tendo em vista que a variável 'cargo com função administrativa $x$ cargo sem função administrativa' também influenciou todos os fatores. $O$ que se constatou junto ao microcampo formado pelos professores que possuem função de gestão foi a defesa da manutenção do status quo, da coesão e partilha de valores, isto é, características de uma manifestação cultural integradora. Relativiza-se, contudo, 0 fato de as respostas revelarem o ponto de vista do gestor, diretamente relacionado à estrutura organizacional de poder.

O tempo de trabalho do professor no IFRN, por sua vez, funciona como outro arcabouço de microcampo existente no interior da instituição. Nesse caso, o microcampo formado pelos indivíduos que trabalhavam há mais tempo avaliaram de maneira positiva dois fatores do construto cultura organizacional - valores e normas e rituais.

Porém, algo controverso foi verificado. Os microcampos relacionados ao campus de lotação do docente foram significantes para a explicação de todas os fatores de cultura organizacional. Especificamente, o microcampo formado pelos docentes lotados no campus Mossoró, em que pese esse não possuir o mesmo tempo de existência do campus Natal-Central, apresentou uma melhor percepção dos fatores de cultura organizacional.

Por fim, os microcampos que apresentram capacidade de influência sobre apenas um fator do estudo foram: os microcampos constituídos de acordo com o regime de dedicação ao trabalho - com dedicação exclusiva ou sem dedicação exclusiva -, que foi significante para o fator que abordava os rituais organizacionais.

A identificação desses microcampos, nas palavras de Hargreaves (1998), ou de (sub)culturas, nas palavras de Van Maanen e Barley (1983), sugere um deslocamento para um plano analítico micro, que permite utilizar-se de lentes microscópicas para observação das manifestações culturais existentes no interior dos grupos docentes no IFRN. Essa observação permitiu verificar que as manifestações culturais no IFRN - e não do IFRN - extrapolam a perspectiva integradora, que enxerga a organização a partir de uma imagem unitária, coesa e delimitada por uma racionalidade superior, partindo para perspectivas diferenciadora em que prevalecem situações de conflito entre diferentes

\begin{tabular}{|l|l|l|l|l|l|}
\hline Regae: Rev. Gest. Aval. Educ. & Santa Maria & v. 11 & n. 20 & e68214, p. 1-27 & 2022 \\
\hline
\end{tabular}


(sub)culturas, e fragmentadora, quando sobressai a ambiguidade presente nas relações entre os integrantes das (sub)culturas. Com isso, defende-se que as variáveis de cultura organizacional, aqui identificadas, não devem ser entendidas como causadoras da cultura organizacional do IFRN, mas devem ser tratadas como consequência de jogos de influência e condicionamentos mútuos presentes na dinâmica organizacional, o que convergiria para uma cultura organizacional no IFRN.

O foco desses apontamentos, todavia, não está no registro, apenas descritivo ou confirmatório da existência ou coexistência de múltiplas (sub)culturas, ou mesmo na identificação da cultura dominante, mas na tentativa de demonstrar as (sub)culturas integrantes dos microcampos docentes, as tensões existentes entre as (sub)culturas, a ambiguidade, ilustrada pela presença de um mesmo indivíduo em diferentes (sub)culturas, conforme seus interesses, e na representação da cultura organizacional a partir da junção de várias (sub)culturas, sem, necessariamente, existir uma relação de subordinação entre elas.

\section{Referências}

BOGDAN, Robert; BILKEN, Sari. Investigação qualitativa em educação. Porto: Porto Editora, 1994.

COCHRAN, William. Sampling techniques. New York: John Wiley \& Sons, 1977.

FERREIRA, Maria Cristina et al. Desenvolvimento de um instrumento brasileiro para avaliação da cultura organizacional. Estudos de Psicologia, Natal, v. 7, n. 2, p. 271-280, 2002.

GIANEZINI, Quelen. A expansão dos institutos federais de educação, ciência e tecnologia no Rio Grande do Sul e o ensino jurídico. SIMPÓSIO BRASILEIRO DE POLÍTICA E ADMINISTRAÇÃO DA EDUCAÇÃO, 25, 2011. São Paulo: Anpae, 2011.

HAIR, Joseph et al. Análise multivariada de dados. Porto Alegre: Bookman, 2009.

HARGREAVES, Andy. Os professores em tempos de mudança: o trabalho e a cultura dos professores na idade pós-moderna. Lisboa: Mc Graw-Hill, 1998.

JULIA, Dominique. A cultura escolar como objeto histórico. Revista Brasileira de História da Educação, Maringá, v. 1, 2001, p. 9-44.

KUENZER, Acácia Zeneida. Educação e trabalho no Brasil: o estado da questão. Brasília: Inep, 1991.

LIMA, Jorge Manuel Ávila. As culturas colaborativas nas escolas: estruturas, processos e conteúdos. Porto: Porto Editora, 2002.

LIMA, Licínio. A Escola como organização e a participação na organização escolar: um estudo da escola secundária em Portugal (1974-1988). Braga: Universidade do Minho, 1992.

MARTIN, Joanne; SIEHL, Caren. Organizational culture and counterculture: An uneasy symbiosis. Organizational dynamics, New York, v. 12, n. 2, 1983, p. 52-64.

MARTIN, Joanne. Cultures in organizations: three perspectives. New York: Oxford University Press, 1992. 
MARTIN, Joanne; FROST, Peter. Jogos de guerra na cultura organizacional: a luta pelo domínio intelectual. In: CLEGG, Stewart; HARDY, Cynthia; NORD, Walter (eds.). Handbook de estudos organizacionais 2, São Paulo: Atlas, p. 219-251, 2001.

MCLAREN, Peter. Multiculturalismo crítico. São Paulo: Cortez, 1997.

PACHECO, Eliezer Moreira. Institutos federais: uma revolução na educação profissional e tecnológica. São Paulo: Moderna, 2011.

PÉREZ GÓMEZ, Angel I. A cultura escolar na sociedade neoliberal. Porto Alegre: Artmed, 2001.

RILEY, Patricia. A Structurationist account of political culture. Administrative Science Quarterly, Ithaca-NY, v. 28, n. 3, 1983, p. 414-437.

SARMENTO, Manuel Jacinto. A vez e a voz dos professores: contributo para o estudo da cultura organizacional da escola primária. Porto: Porto Editora, 1994.

$\mathrm{SMIRCICH}$, Linda. Concepts of culture and organizational analysis. Administrative Science Quaterly, Ithaca-NY, v. 28, 1983, p.339-358.

STAKE, Robert. Investigación con estudio de casos. Madrid: Morata, 1999.

TABACHNICK, Barbara; FIDELL, Linda. Using multivariate statistics. New York: Harper \& Row, 1989.

TEIXEIRA, Lucia Helena. Cultura organizacional da escola: uma perspectiva de análise e conhecimento da unidade Escolar. Revista Brasileira de Política e Administração da Educação, Porto Alegre, v. 16, n. 1, 2000, p. 7-22.

TENTI FANFANI, Emilio. La condición docente: datos para el análisis comparado Argentina, Brasil, Perú y Uruguay. Buenos Aires: Siglo Veintiuno, 2007.

TORRES, Leonor Lima. Cultura organizacional em contexto educativo: sedimentos culturais e processos de construção do simbólico numa escola secundária. Braga: Centro de Investigação em Educação da Universidade do Minho, 2004.

TORRES, Leonor Lima. Cultura organizacional no contexto escolar: o regresso à escola como desafio na reconstrução de um modelo teórico. Ensaio: avaliação e políticas públicas em Educação, Rio de Janeiro, v. 13, n. 49, 2005, p. 435-451.

TORRES, Leonor Lima. Liderança singular na escola plural: as culturas da escola perante o processo de avaliação externa. Revista Lusófona de Educação, Lisboa, v. 23, 2013, p. 51-76.

VIÑAO FRAGO, Antonio. Culturas escolares, reformas e innovaciones: entre la tradición y el cambio. JORNADAS ESTATALES DEL FÓRUM EUROPEO DE ADMINISTRADORES DE LA EDUCACIÓN, 8, 1996. Actas ... Murcia: Feae, 1996, p. 17-29.

VAN MAANEN, John. Reclaiming qualitative methods for organizational research: a preface. Administrative Science Quarterly, Ithaca-NY, v. 24, n. 4, 1979, p. 520-526.

VAN MAANEN, John; BARLEY, Stephen. Cultural organization: fragments of a theory. Cambridge/MA: Alfred P Sloan School of Management, 1983. 
Jássio Pereira de Medeiros é professor no Instituto Federal de Educação, Ciência e Tecnologia do Rio Grande do Norte.

Orcid: https://orcid.org/0000-0003-0922-7087.

Endereço: Avenida Senador Salgado Filho, 1559 - 59015-000 - Natal - RN - Brasil.

E-mail: jassio.pereira@ifrn.edu.br.

Critérios de autoria: o autor foi o único responsável pela concepção, criação e consolidação do artigo.

Recebido em 21 de outubro de 2021.

Aceito em 3 de janeiro de 2022.

(c) (i) (\$) $\ominus$

(c) $\mathrm{BY}$ ND 